\title{
Genetic epidemiology of psoriasis and psoriatic arthritis
}

\author{
P Rahman, J T Elder
}

Ann Rheum Dis 2005;64(Suppl II):ii37-ii39. doi: 10.1136/ard.2004.030775

Psoriasis and psoriatic arthritis ( $P s A)$ are interrelated disorders, as most patients with PsA also have psoriasis. Thus it is not surprising that epidemiological and immunogenetic studies have uncovered important links between these two disorders. Both disorders are highly heritable, and the prevalence of psoriasis is 19 times higher among first degree relatives of probands with PSA compared with the general population. Multiple human leucocyte antigen (HLA) associations are shared between psoriasis and PsA, though the magnitudes of these associations differ between the diseases. Genome-wide linkage studies have noted overlapping regions of significance for these two disorders within and outside the major histocompatibility complex (MHC) region. Thus, exploration of the genetic basis of psoriasis will likely strengthen the contention of an underlying genetic susceptibility for PsA and vice versa.

$\mathrm{P}$ soriasis and psoriatic arthritis (PsA) are clearly complex genetic disorders that result from an interplay between multiple genetic and environmental factors. Although the exact aetiologies of psoriasis and PsA are unclear, cumulative evidence implicates a substantive role for genetic factors in both these diseases with respect to disease susceptibility and expression. ${ }^{12}$ The genetic basis of psoriasis and PsA is supported by family based investigations, population based epidemiological studies, association studies with human leucocyte antigens (HLAs), genome-wide linkage scans, and candidate gene studies within and outside the major histocompatibility complex (MHC) region.

\section{TWIN STUDIES: ESTABLISHING A GENETIC COMPONENT}

One of the most compelling ways to implicate genetics in disease is to establish an increased disease concordance between monozygotic twins when compared with dizygotic twins. Indeed this is the case in psoriasis, where there is a threefold increased risk of psoriasis in monozygotic twins compared to fraternal twins (reviewed in reference 3 ). However, as the concordance for psoriasis is never $100 \%$ among monozygotic twins, and can be as low as $35 \%$, the data suggest that environmental factors also play an important role.

At present there are no published reports of twin studies in PsA, probably due to its lower frequency. However, Moll and Wright reported a triplet born with an identical twin and a non-identical third triplet. ${ }^{4}$ The identical twins both developed psoriasis with one having spondylitis and the other polyarthritis. The non-identical triplet had no psoriasis or arthritis.

\section{POPULATION BASED STUDIES: QUANTITATING THE MAGNITUDE OF GENETIC BURDEN}

The magnitude of genetic contribution for a disease can be estimated by assessing the relative proportion of disease in the siblings (or another given degree of relatives) compared with the prevalence of disease in the general population. This parameter originally formulated by Risch, is denoted as $\lambda_{R}$, where R represents the degree of relatedness. ${ }^{5}$ Three major population based epidemiological studies, from the Faroe Islands and Sweden, ${ }^{67}$ and one clinic based study from Germany, ${ }^{8}$ have revealed a substantially higher incidence of psoriasis in relatives compared with the general population. The calculated $\lambda_{1}$ is 8 for the Faroe Islands cohort, 4 for the Swedish cohort, and 10 for the German cohort. ${ }^{13}$ Risch also developed a formula for using risk ratios among relatives of differing relatedness to obtain information about genetic models. When the risk ratio $\left(\lambda_{R}-1\right)$ decreases by a factor of greater than 2 between the first and second degrees of relatedness, the data are consistent with a multilocus model. ${ }^{5}$ As this factor was 7 in the Faroe Islands study and 8 in the Swedish study, a multilocus model for psoriasis is predicted. ${ }^{3}$

Another method for quantitating the burden of genetic disease is to estimate the heritability of the disorder, which refers to the proportion of variability of a trait attributed to a genetic factor. The heritability can be estimated from twin studies or population based case-control studies. The heritability for psoriasis has been estimated to be between $60 \%$ and $90 \%$ for psoriasis (reviewed in reference 3 ).

Epidemiological studies demonstrating the magnitude of genetic burden of PsA are sparse. The most robust study estimating the strong familial clustering of PsA was conducted by Moll and Wright in 1973. ${ }^{4}$ First and second degree relatives of 88 patients with PsA were assessed. Probands were ascertained from a hospital population, and sampling was consecutive and unselective. Of the probands with PsA, $12.5 \%$ had at least one relative with confirmed PsA. Of the 181 first degree relatives assessed, 10 relatives had PsA, including five siblings. Thus the overall prevalence of PsA among first degree relatives was 5.5\%. As the calculated prevalence of PsA in the UK population is $0.1 \%$, the risk for affected first degree relatives $\left(\lambda_{1}\right)$ is 55 , a figure substantially higher than those obtained for psoriasis (ranging from 4 to 10, as reviewed above). This study also noted a 19-fold increase in prevalence of psoriasis among first degree relatives of probands with PsA compared with the general population. The remaining studies assessing the familial tendency of PsA will not be reviewed here as they were small, often with poor phenotype ascertainment and inadequate controls. As reviewed by Moll and Wright, these remaining studies also note familial clustering of PsA. ${ }^{4}$

\section{MODE OF INHERITANCE}

It is now universally acknowledged that psoriasis and PsA are consistent with a multifactorial pattern of inheritance. ${ }^{12}$ However, there are scattered reports where an autosomal dominant and autosomal recessive pattern of inheritance for psoriasis have been proposed. For instance, transmission through many generations of a large kindred supports dominant inheritance, ${ }^{9}$ and Swanbeck et al found that a recessive mode of inheritance was compatible with

Abbreviations: HLA, human leucocyte antigen; MHC, major histocompatibility complex; PsA, psoriatic arthritis 
recurrence risks among first degree relatives. ${ }^{10}$ Even in these reports, however, a multifactorial model cannot be ruled out.

A non-mendelian mode of transmission referred to as genomic imprinting has also been proposed for psoriasis and PsA, ${ }^{11}{ }^{12}$ as it has for several other autoimmune diseases. ${ }^{13}$ Genomic imprinting refers to an epigenetic effect that causes differential expression of a gene depending on the sex of the transmitting parent. ${ }^{14}$ The imprinting process, exemplified by the Prader-Willi syndrome, ${ }^{14}$ allows gene expression from only the maternally or paternally derived chromosome. In one study, ${ }^{11}$ the birthweight of children of parents with psoriasis was found to be influenced by the sex of the parent with psoriasis, with offspring of males with psoriasis weighing $270 \mathrm{~g}$ more than offspring of females with psoriasis. The same authors reanalysed the Faroe Island kindreds and noted a higher penetrance of psoriasis if the father was affected or a presumed gene carrier. Interestingly, others have also noted evidence of a parental sex effect in psoriasis, with more psoriatic probands having an affected father than an affected mother. ${ }^{15}$

A parent-of-origin effect has also been demonstrated in PsA. ${ }^{12}$ We noted that the proportion of probands with an affected father (0.65) was significantly greater than the expected proportion of $0.5(\mathrm{p}=0.001) .{ }^{12}$ Similar trends were noted in the offspring and second degree relatives of the proband. Furthermore, a recent linkage study in PsA noted significant linkage only when assessing the transmission of alleles of paternal origin. ${ }^{16}$ Thus the presence of this epigenetic phenomenon should be considered for incorporation in the genetic model for linkage studies, as its inclusion may influence the evidence for a linkage.

\section{DECREASING CLINICAL HETEROGENEITY}

Henseler and Christophers in 1985 noted that type I psoriasis, defined by the onset of psoriasis before age 40 years, had a stronger genetic basis as a greater proportion of patients had a family history of psoriasis, stronger HLA associations (HLACw6, HLA-DR7, HLA-B13, and HLA-Bw57) and more severe psoriasis. ${ }^{17}$ Patients with type II psoriasis were characterised by a later age of onset (after 40 years) and were found to have lower familial tendency. The risk ratio for first degree relatives $\left(\lambda_{1}\right)$ for type I psoriasis was 10 , compared with 1 or 2 for those with type II psoriasis. ${ }^{1}$ As identifying a subset of psoriasis decreases the heterogeneity of this complex disorder, most genetic studies now focus exclusively on probands with type I psoriasis.

We noted a similar trend in PsA, although this finding has yet to be substantiated due to a paucity of studies. ${ }^{18} \mathrm{We}$ stratified PsA patients according to the age of onset of psoriasis (before or after the age of 40 years). PsA patients with early onset psoriasis were more likely to have a family history of psoriasis or PsA $(60 \%$ in early onset $v 30 \%$ in late onset; $p=0.001)$. Significant differences in other clinical features such as skin lesions preceding joint lesions, a lower number of actively inflamed joints at presentation, a higher frequency of spondyloarthropathy, and differential expression of HLA antigens (HLA-B17, HLA-Cw6) in the early onset group were also noted. In the light of these findings, inclusion of the age of onset of psoriasis a priori, as a potential stratification variable, may also reduce the heterogeneity in PsA.

\section{PENETRANCE OF DISEASE}

Swanbeck et al presented empirical data that may be of relevance for genetic counselling. ${ }^{10}$ After assessing over 3000 families in which one or both parents had psoriasis, the calculated lifetime risk of getting psoriasis if no parent, one parent, or both parents have psoriasis was found to be 0.04 , 0.28 , and 0.65 , respectively. If there was already one affected child in the family, the corresponding risks were $0.24,0.51$, and 0.83 , respectively.

In a much smaller study of PsA, we reported that if there was already one affected child in the family, the corresponding risk for another affected sibling was $0.10,0.22$, or 0.31 if no parents was affected, the mother was affected, or the father was affected, respectively. ${ }^{19}$

\section{GENE IDENTIFICATION STUDIES Linkage studies}

Two common strategies are presently employed to elucidate genetic determinants of complex disease. One strategy, positional cloning, is to isolate the disease gene by its chromosomal location without any prior knowledge of the position or function of the gene. Positional cloning requires collection of families with multiple affected individuals so that linkage analysis can be performed. This can be done by one of two methods: constructing a model to explain the inheritance of disease in the pedigrees and then estimating the recombination fraction for a given pedigree (referred to as the traditional or parametric method); or ascertaining affected family members, typically affected sibling pairs, and assessing the allele sharing (referred to as the allele sharing or non-parametric method). The premise for the second method is the fact that in the presence of linkage between a marker and disease, sets of relatives who share the same disease status are more likely to share alleles at the marker locus than the value of $50 \%$ that would be predicted by chance.

Both these linkage methods have been used to elucidate the genetics of psoriasis. The psoriasis susceptibility loci that have been mapped using linkage methods include: PSORSI on 6p21.3, PSORS2 on 17q, PSORS3 on 4q, PSORS4 on lcen$\mathrm{q} 21$, PSORS5 on $3 \mathrm{q} 21$, PSORS6 on 19p, PSORS7 on 1p, and PSORS9 on 4q31..$^{20-27}$ Additional putative psoriasis candidate loci have been reported on $16 q$ and $20 p .^{28}$ The loci on $6 p$ and $17 \mathrm{q}$ have been replicated with independent linkage studies. $^{28}{ }^{29}$ The replication for some other loci has proved to be quite difficult. To confirm previously reported linkages to psoriasis, the International Psoriasis Genetics Consortium analysed 942 affected sibling pairs (ASPs) from 710 pedigrees for 53 polymorphic microsatellites spanning 14 psoriasis candidate regions. ${ }^{30}$ Maximum LOD score (MLS) analysis of ASPs yielded allele sharing of $60 \%$ for markers within the MHC. This study once again highlights the importance of this region in the pathogenesis of psoriasis. Across the remainder of the genome, the strongest evidence of allele sharing was obtained on 16q and 10q22-q23. The HLA region was also highlighted in a recent sib pair analysis where there was higher than expected haplotype sharing among sib pairs concordant for PsA. ${ }^{31}$

To date only one genome-wide scan has been completed in PsA, and this study localised a candidate region on chromosome 16q. ${ }^{16}$ This genome scan was performed using 1000 microsatellite markers in 178 patients with PsA from 39 Icelandic families. The authors reported an LOD score of 2.17 on chromosome 16q, and further analysis, conditional on parental transmission to affected individuals, resulted in an LOD score of 4.19. The significance of these linkages noted in psoriasis and PsA is described elsewhere in this supplement. ${ }^{32}$

\section{Association studies}

Association of psoriasis and PsA with alleles in the MHC region has been recognised for over three decades, and presently there are a plethora of association studies for both these disorders with HLA alleles. For instance class I antigens HLA-B13, HLA-B17 and its split HLA-B57, and HLA-Cw6 have consistently shown a positive association with 
psoriasis across various population studies. ${ }^{33-35}$ The presence of HLA-CW*0602 is associated with more severe and early onset psoriasis ${ }^{36}$ and was found in $100 \%$ of patients with guttate psoriasis. ${ }^{37}$ Meanwhile, HLA-Cw ${ }^{*} 0602$ is increased among those with PsA and is also associated with an earlier age of onset of psoriasis. ${ }^{38} 39$ HLA-B27, HLA-B38, and HLA-B39 have also consistently been noted to have an increased frequency in PsA cases compared with controls. ${ }^{34}{ }^{45}$ With respect to disease expression, HLA-B27 is associated with back involvement, while HLA-B38 and HLAB39 occurred more frequently among patients with peripheral polyarthritis. ${ }^{34} 3540$ These and other proposed candidate genes in psoriasis and PsA are discussed elsewhere in this supplement. ${ }^{32}$

Focus has now also been directed at regions outside the MHC region. With the advent of single nucleotide polymorphism technology and high throughput genotyping, the potential for association and linkage disequilibrium methods has expanded greatly. The linkage and association methods should not be thought of as being mutually exclusive strategies but rather complementary, as association studies are often being attempted in regions that have been localised by previous linkage studies.

In summary, there is a clear genetic contribution to psoriasis and PsA. Although there will likely be some distinct genetic differences between these two disorders, epidemiological and immunological evidence suggests that some genetic determinants are likely to be shared between these two diseases. With the strong genetic contribution to psoriasis and PsA, coupled with rapidly advancing sequencing and bioinformatics platforms, elucidation of the major genetic determinants of these diseases should be feasible.

\section{Authors' affiliations}

P Rahman, St Clare's Mercy Hospital, Memorial University of Newfoundland, St John's, Newfoundland, Canada

J T Elder, Departments of Dermatology and Radiation Oncology, University of Michigan, Ann Arbor, Ml; and Ann Arbor Veterans Affairs Health System, Ann Arbor, MI, USA

JTE acknowledges support from the National Institute of Arthritis, Musculoskeletal, and Skin Diseases, the National Psoriasis Foundation, the Babcock Memorial Trust, and the Ann Arbor Veterans Affairs Health System.

PR is a CIHR New Investigator and Arthritis Society Scholar

Correspondence to: Dr P Rahman, St Clare's Mercy Hospital, 1 South, 154 LeMarchant Rd, St John's, Newfoundland, Canada A1C-5B8; prahman@mun.ca

\section{REFERENCES}

1 Elder JT, Nair RP, Henseler T, Jenisch S, Stuart P, Chia N, et al. The genetics of psoriasis 2001: the odyssey continues. Arch Dermatol 2001;137:1447-54.

2 Gladman DD, Rahman P. Psoriatic arthritis. In: Ruddy S, Harris ED, Sledge CB, Budd RC, Sergent JS, eds. Kelly's Textbook of Rheumatology, 6th edn. Philadelphia: WB Saunders Co, 2001:1071-9.

3 Elder JT, Nair RP, Guo SW, Henseler T, Christophers E, Voorhees JJ. The genetics of psoriasis. Arch Dermatol 1994;130:216-24.

4 Moll JM, Wright V. Familial occurrence of PsA. Ann Rheum Dis 1973;32:181-201.

5 Risch N. Linkage strategies for genetically complex traits. I. Multilocus model. Am J Hum Genet 1990;46:222-8.

6 Lomholt G. Psoriasis: prevalence, spontaneous course, and genetics [published MD thesis]. Copenhagen: GEC GAD, 1963:157-84.

7 Hellgren L. Psoriasis: the prevalence in sex, age and occupational groups in total populations in Sweden; morphology, inheritance and association with other skin and rheumatic diseases [published MD thesis]. Stockholm: Almqvist and Wiksell, 1967:65-71.

8 Christophers E, Henseler T. Psoriasis type I and type II as subtypes of nonpustular psoriasis. In: Roenigk H, Maibach H, eds. Psoriasis. New York: Marcel Dekker, 1990:15-21.

9 Abele DC, Dobson RL, Graham JB. Heredity and psoriasis: study of a large family. Arch Dermatol 1963;88:88-99.

10 Swanbeck G, Inerot A, Martinsson T, Enerback C, Enlund F, Samuelsson L, et al. Genetic counselling in psoriasis: empirical data on psoriasis among first- degree relatives of 3095 psoriatic probands. Br J Dermatol 1997; 137:939-42.

11 Traupe H, van Gurp PJ, Happle R, Boezeman J, van de Kerkhof PC. Psoriasis vulgaris, fetal growth, and genomic imprinting. Am J Med Genet 1992;42:649-54.

12 Rahman P, Gladman DD, Schentag C, Petronis A. Excessive paternal transmission in psoriatic arthritis. Arthritis Rheum 1999;42:1228-31.

13 Morison IM, Reeve AE. A catalogue of imprinted genes and parent-of-origin effects in humans and animals. Hum Mol Genet 1998;7:1599-609.

14 Langlois S, Lopez-Rangel E, Hall JG. New mechanisms for genetic disease and non-traditional modes of inheritance. Adv Pediatr 1995;42:91-111.

15 Burden AD, Javed S, Bailey M, Hodgins M, Connor M, Tillman D. Genetics of psoriasis: paternal inheritance and a locus on chromosome 6p. J Invest Dermat 1998; 110:958-60.

16 Karason A, Gudjonsson JE, Upmanyu R, Antonsdottir AA, Hauksson VB, Runasdottir $\mathrm{EH}$, et al. A susceptibility gene for psoriatic arthritis maps to chromosome 16p: evidence for imprinting. Am J Hum Genet 2003:72:125-31, Epub 9 December 2002

17 Henseler T, Christophers E. Psoriasis of early and late onset: characterization of two types of psoriasis vulgaris. J Am Acad Dermatol 1985;13:450-56.

18 Rahman P, Gladman DD, Schentag CT. Immunogenetic profile of patients with psoriatic arthritis varies according to the age at onset of psoriasis. Arthritis Rheum 1999;42:822-3.

19 Rahman P, Gladman D, Khraishi M, Hamilton S, Tobin Y, Hefferton D, et al. Influence of parental history on the recurrence risk of siblings with psoriatic arthritis [abstract]. J Rheumatol 2003;30:1885

20 Trembath RC, Clough RL, Rosbotham JL, Jones AB, Camp RD, Frodsham A, et al. Identification of a major susceptibility locus on chromosome $6 p$ and evidence for further disease loci revealed by a two stage genome-wide search in psoriasis. Hum Mol Genet 1997;6:813-20.

21 Tomfohrde J, Silverman A, Barnes R, Fernandez-Vina MA, Young M, Lory D, et al. Gene for familial psoriasis susceptibility mapped to the distal end of human chromosome 17q. Science 1994;264:1141-5.

22 Matthews D, Fry L, Powles A, Weber J, McCarthy M, Fisher E, et al. Evidence that a locus for familial psoriasis maps to chromosome 4q. Nature Genet 1996;14:231-3.

23 Capon F, Novelli G, Semprini S, Clementi M, Nudo M, Vultaggio P, et al. Searching for psoriasis susceptibility genes in Italy: genome scan and evidence for a new locus on chromosome 1. J Invest Derm 1999;1 12:32-5.

24 Enlund F, Samuelsson L, Enerback C, Inerot A, Wahlstrom J, Yhr M, et al. Psoriasis susceptibility locus in chromosome region 3q21 identified in patients from southwest Sweden. Eur J Hum Genet 1999;7:783-90.

25 Lee YA, Ruschendorf F, Windemuth C, Schmitt-Egenolf M, Stadelmann A, Nurnberg $G$, et al. Genomewide scan in German families reveals evidence for a novel psoriasis-susceptibility locus on chromosome 19p13. Am J Hum Genet 2000;67:1020-4, Epub 13 Sep 2000.

26 Veal CD, Clough RL, Barber RC, Mason S, Tillman D, Ferry B, et al. Identification of a novel psoriasis susceptibility locus at $1 p$ and evidence of epistasis between PSORS1 and candidate loci. J Med Genet 2001:38:7-13.

27 Zhang XJ, He PP, Wang ZX, Zhang J, Li YB, Wang HY, et al. Evidence for a major psoriasis susceptibility locus at 6p21 (PSORS1) and a novel candidate region at $4 \mathrm{q} 31$ by genome-wide scan in Chinese Hans. J Invest Dermatol 2002;119:1361-6.

28 Nair RP, Henseler T, Jenisch S, Stuart P, Bichakjian CK, Lenk W, et al. Evidence for two psoriasis susceptibility loci (HLA and 17q) and two novel candidate regions (16q and 20p) by genome-wide scan. Hum Mol Genet 1997;6:1349-56.

29 Enlund F, Samuelsson L, Enerback C, Inerot A, Wahlstrom J, Yhr M, et al. Analysis of three suggested psoriasis susceptibility loci in a large Swedish set of families: confirmation of linkage to chromosome 6p (HLA region), and to $17 q$, but not to $4 \mathrm{q}$. Hum Hered 1999;49:2-8.

30 International Psoriasis Genetics Consortium: The International Psoriasis Genetics Study: assessing linkage to 14 candidate susceptibility loci in a cohort of 942 affected sib pairs. Am J Hum Genet 2003;73:430-7.

31 Gladman DD, Farewell VT, Pellett F, Schentag C, Rahman P. HLA is a candidate region for psoriatic arthritis: evidence for excessive HLA sharing in sibling pairs. Hum Immunol 2003;64:887-9.

32 Kreuger JG, Bowcock A. Psoriasis pathophysiology: current concepts of pathogenesis. Ann Rheum Dis 2005;64(suppl II):ii30-6.

33 Bhalerao J, Bowcock AM. The genetics of psoriasis: a complex disorder of the skin and immune system. Hum Mol Genet 1998;7:1537-45.

34 Gladman DD, Anhorn KAB, Schachter RK, Mervart H. HLA antigens in psoriatic arthritis. J Rheumatol 1986;13:586-592.

35 Eastmond CJ. Genetics and HLA antigens. In: Wright V, Helliwell P, eds. In: Baillière's Clinical Rheumatology. Psoriatic Arthritis. London: Ballière Tindall, 1994;8:263-76.

36 Gudjonsson JE, Karason A, Antonsdottir AA, Runarsdottir EH, Gulcher JR, Stefansson K, et al. HLA-Cw6-positive and HLA-Cw6-negative patients with psoriasis vulgaris have distinct clinical features. J Invest Dermatol 2002; 1 18:362-5

37 Mallon E, Bunce M, Savoie H, Rowe A, Newson R, Gotch F, et al. HLA-C and guttate psoriasis. Br J Dermatol 2000;143:1177-82.

38 Gladman DD, Cheung C, Ng CM, Wade JA. HLA C-locus alleles in psoriatic arthritis. Human Immunol 1999;60:259-61

39 Al-Heresh AM, Proctor J, Jones SM, Dixey J, Cox B, Welsh K, et al. Tumour necrosis factor $\alpha$ polymorphisms and the HLA-Cw*0602 allele in psoriatic arthritis. Rheumatology (Oxford) 2002;41:525-30.

40 Espinoza LR, Vasey FB, Gaylord SW, Dietz C, Bergen L, Bridgeford P, et al. Histocompatibility typing in the seronegative spondyloarthropathies: a survey. Semin Arthritis Rheum 1982;11:375-81. 